\title{
Improved Lignocellulose Degradation Efficiency by Fusion of $\beta$-Glucosidase, Exoglucanase, and Carbohydrate-Binding Module from Caldicellulosiruptor saccharolyticus
}

\author{
Jilin Xia, ${ }^{a}$ Yu Yu, ${ }^{a}$ Huimin Chen, ${ }^{a}$ Jia Zhou, ${ }^{\text {a,b }}$ Zhongbiao Tan, ${ }^{\text {a,b }}$ Shuai He,,${ }^{\text {a,bc }}$ \\ Xiaoyan Zhu, ${ }^{\text {a,b }}$ Hao Shi, ${ }^{\text {a,b }}$ Pei Liu, ${ }^{\text {a,b,c }}$ Muhammad Bilal, ${ }^{a}$ and Xiangqian Li ${ }^{\text {a,b, } *}$
}

\begin{abstract}
Bifunctional cellulases with $\beta$-glucosidase (Bgl1), exoglucanase (Exo5), and carbohydrate-binding modules (CBMs) from Caldicellulosiruptor saccharolyticus were fused to yield several recombinant plasmids, Bgl1CBM-Exo5, Bgl1-2CBM-Exo5, and Bgl1-3CBM-Exo5. The fused enzymes possessed both $\beta$-glucosidase and exoglucanase activities and were used to improve the degradation efficiency of lignocellulosic biomass. The optimal temperature of Bgl1-3CBM-Ex05 was $70^{\circ} \mathrm{C}$, which was the same as $\mathrm{Bgl1}$, and the optimal temperature of the other two enzymes was $80^{\circ} \mathrm{C}$, which was the same as Exo5. The optimal pH of fused enzymes was 4 to 5, the same as Exo5, but the optimal pH of Bgl1 was 5.5. Compared with Bgl1-CBM-Exo5 and Bgl1-2CBM-Exo5, the hydrolysis efficiency of Bgl1-3CBM-Exo5 on sodium carboxymethyl cellulose (CMC-Na) was increased by $67 \%$ and $50 \%$, respectively. The activities of these enzymes on CMC-Na were increased by 128 to $192 \%$ when $10 \mathrm{mM} \mathrm{MnCl}_{2}$ was added. Filter paper, microcrystalline cellulose (MCC), steam-pretreated rice straw, rice straw, and wheat straw were efficiently degraded by these fused enzymes. Specific activities of the fusion enzymes on MCC reached 34.4 to $76.4 \mathrm{U} / \mu \mathrm{mol}$. The results indicated that bifunctional cellulases fused with CBMs were functional on cellulosic biomass, and CBMs contributed to further deconstruction of MCC and other natural substrates.
\end{abstract}

Keywords: $\beta$-glucosidase; Exoglucanase; Fusion enzymes; CBM; Caldicellulosiruptor saccharolyticus

Contact information: a: School of Life Science and Food Engineering, Huaiyin Institute of Technology, Huaian 223003, China; b: Jiangsu Provincial Engineering Laboratory for Biomass Conversion and Process Integration, Huaiyin Institute of Technology, Huaian 223003, China; c: Jiangsu Provincial Key Construction Laboratory of Probiotics Preparation, Huaiyin Institute of Technology, Huaian 223003, China;

* Corresponding author: lixq2002@126.com

\section{INTRODUCTION}

Cellulases from thermophilic bacteria or fungi have attracted worldwide attention due to their tremendous potential in the utilization of the lignocellulosic biomass (Chao et al. 2017). Multiple cellulases have been applied for the complete degradation of lignocellulose. However, $\beta$-glucosidase has been found to be a rate-limiting enzyme for the hydrolysis of cellulose into monosaccharides, which may be attributed to its intolerance to glucose (Yang et al. 2015). Beta-glucosidase from Caldicellulosiruptor saccharolyticus exhibits the properties of high-temperature resistance, which is conducive to industrial applications (Hong et al. 2009). Nevertheless, the low hydrolysis 
efficiency and narrow spectrum of applicable substrates tend to hinder the development of industrial applications of cellulases (Mariano et al. 2014; Singh et al. 2016). Moreover, C. saccharolyticus genome sequence data suggests that some gene clusters encoded glycoside hydrolases with dual catalytic domains ( $\mathrm{Hj}$ et al. 2008). Some exoglucanases of bifunctional glycoside hydrolases from $C$. saccharolyticus are essential for the decomposition of microcrystalline cellulose (MCC) (Blumerschuette et al. 2012). Therefore, the construction of fusion enzymes is expected to improve the degradation efficiencies of $\beta$-glucosidase and exoglucanase on MCC and other un-pretreated biomasses.

Hong et al. $(2006 ; 2007)$ constructed XynA-Cel5C and BglB-Cel5C without a linker and carbon-binding module (CBM). XynA-Cel5C exhibited no cellulase and xylanase activity, whereas $\mathrm{BglB}-\mathrm{Cel} 5 \mathrm{C}$ showed a very low activity on sodium carboxymethyl cellulose (CMC-Na) but no activity on $p$-nitrophenyl- $\beta$-Dglucopyranoside ( $p$ NPG). These results suggested that misfolding or intramolecular interactions between two catalytic domains inactivate the fused enzymes (Hong et al. 2006). Kim et al. (2015) reported that Xyl10g-GS-Cel5B with a glycine-serine linker (GS) showed lower specific activity than Xyl10g or Cel5B. However, Cel5B-GS-Xyl10g presented no activity due to misfolding or inappropriate interactions. Moreover, Duedu and French (2016) carried out the fusion of exoglucanase and xylanase into CxnA. The fusion enzyme activity assays revealed that CxnA, containing CBM and a linker, improved the efficiency of cellulose degradation. This higher activity of the fusion enzyme may be attributed to inserting the linker and CBM into two catalytic domains. These results also indicated that $\mathrm{CBM}$ may contribute to each domain becoming more flexible. However, CxnA cannot be directly applied in degrading natural substrates, e.g., wheat straw (WS) and rice straw (RS).

Interestingly, in a natural endoglucanase, five CBMs are functional to achieve a high degree of activity and processing capability (Zhang et al. 2018). Shi et al. (2018) documented that the activities of the endoglucanase Cel12B on MCC were increased by 0.6- to 24-fold after integrating it with heterogeneous CBMs. Moreover, Brunecky et al. (2013) reported that CelA, containing one CBM3c and two CBM3b from $C$. bescii outperformed mixtures of commercially relevant Trichoderma reesei Cel7A and Acidothermus cellulolyticus Cel5A.

In this study, coding sequences for $\beta$-glucosidase (Bg11), CBM, and exoglucanase (Exo5) were fused to produce recombinant genes Bgl1-CBM-Exo5, Bgl1-2CBM-Exo5, and Bgl1-3CBM-Exo5, coding for the two enzymes linked by 1, 2, and $3 \mathrm{CBMs}$, respectively. The activities of these fused enzymes influenced by different CBMs were investigated. The optimal temperature, $\mathrm{pH}$, and thermostability, as well as the effects of chemicals on the activities and the spectrum of substrates of the fusion enzymes, were investigated.

\section{EXPERIMENTAL}

\section{Materials}

Strains, vectors, growth conditions and reagents

E. coli DH5a and BL21(DE3), procured from Novagen (Madison, WI, USA), were used as cloning and expression host cell, respectively. A pET28a vector from Novagen was used both for cloning as well as expression purposes. Genes encoding 
CBM3b-exoglucanase (UniProt ID: A4XIF7), CBM3c-CBM3b (GenBank: AAA91086.1), and $\beta$-glucosidase (GenBank: YP001179893) were derived from $C$. saccharolyticus, whose genome was stored in the Jiangsu Provincial Engineering Laboratory for Biomass Conversion and Process Integration. E. coli DH5a and BL21(DE3) were cultured in Luria-Bertani (LB) medium with a final concentration of 50 $\mu \mathrm{g}$ kanamycin at $37{ }^{\circ} \mathrm{C}$ or $25{ }^{\circ} \mathrm{C}$. BU-Taq Plus $2 \mathrm{X}$ Master PCR Mix, restriction endonuclease, and T4 DNA ligase were purchased from Biouniquer (Beijing, China), Thermo Scientific (Waltham, MA, USA), and New England Biolabs (Ipswich, MA, USA), respectively, and used for molecular cloning. A His-Bind Purification kit was obtained from Novagen. All other reagents were of the highest-purity grade and supplied by Sangon Biotech (Shanghai, China).

\section{Methods}

Fusion genes and recombinant plasmids construction

For the construction of the fusion enzymes, nine primer sets (P1 through P9) were used to amplify genes of $\beta$-glucosidase, CBM3c-CBM3b, and CBM3b-exoglucanase from the genome of $C$. saccharolyticus (Table 1). Restriction sites were introduced into the primers (underlined, Table 1). Figure 1 illustrates the complete process for constructing fusion enzymes. For fusion of Bgl1-CBM-Exo5, the CBM3b-exoglucanase gene was amplified by using P8 and P9 and inserted into pET28a vector. The $\beta$ glucosidase gene was amplified by using P1 and P2 primers pair and ligated at the end of the N-terminal of CBM3b-exoglucanase. For Bgl1-2CBM-Exo5 construction, the $\beta$ glucosidase gene amplified by using $\mathrm{P} 1$ and $\mathrm{P} 3$ primers was inserted at the end of $\mathrm{N}$ terminal of CBM3b-exoglucanase. Moreover, a new CBM3b gene from CelA of $C$. saccharolyticus was also amplified by using P4 and P5 and ligated between $\beta$ glucosidase and CBM3b-exoglucanase gene. Finally, a new CBM3c-CBM3b gene amplified from CelA of $C$. saccharolyticus using P6 and P7 was integrated between $\beta$ glucosidase and CBM3b-exoglucanase gene to construct Bgl1-3CBM-Exo5. The fusion proteins all contained a natural linker and His $(6 \mathrm{x})$ tags at the $\mathrm{C}$-terminal end. The recombinant plasmids were verified by sequencing and transformed into E. coli BL21(DE3).

Table 1. Oligonucleotide Primers Used in the Fusion Enzymes

\begin{tabular}{|c|c|}
\hline Primers & 5'-3' Nucleotide Sequence \\
\hline P1 & AACGATCCATGGCTATGAGTTTCCCAAAAGGATT \\
\hline P2 & AACGATGAGCTCCGAATTTTCCTTTATATACTG \\
\hline P3 & AACGATGGATCCCGAATTTTCCTTTATATACTG \\
\hline P4 & AACGATGGATCCTCTGGGGTAACAACATCATC \\
\hline P5 & AACGATGAGCTCACTCGGCTCCTGTCCCCA \\
\hline P6 & AACGATGGATCCTTCTTTGTTGAAGCTGGTATA \\
\hline P7 & AACGATGAGCTCCCCTGCTCCACTCTTAAATC \\
\hline P8 & AACGATGAGCTCGGGGTAACAACATCATCTC \\
\hline P9 & AACGATCTCGAGTTTTGAAGCTGGAACTGGCTC \\
\hline
\end{tabular}


Expression and assays for the fusion enzymes activities

Small-scale protein expression was carried out to detect $\beta$-glucosidase and exoglucanase activities of the fusion enzymes. Briefly, $100 \mathrm{~mL}$ of cell cultures were harvested, washed with sterile water, and resuspended in $10 \mathrm{~mL}$ of sterile water. Cells were disrupted by sonication and centrifuged at $10,000 \times \mathrm{g}$ and $4{ }^{\circ} \mathrm{C}$ for $20 \mathrm{~min}$. The resulting precipitate was removed, and the supernatant was used to assay cellulase and $\beta$ glucosidase activities. In addition, the fusion proteins were also determined by sodium dodecyl sulfate polyacrylamide gel electrophoresis (SDS-PAGE).

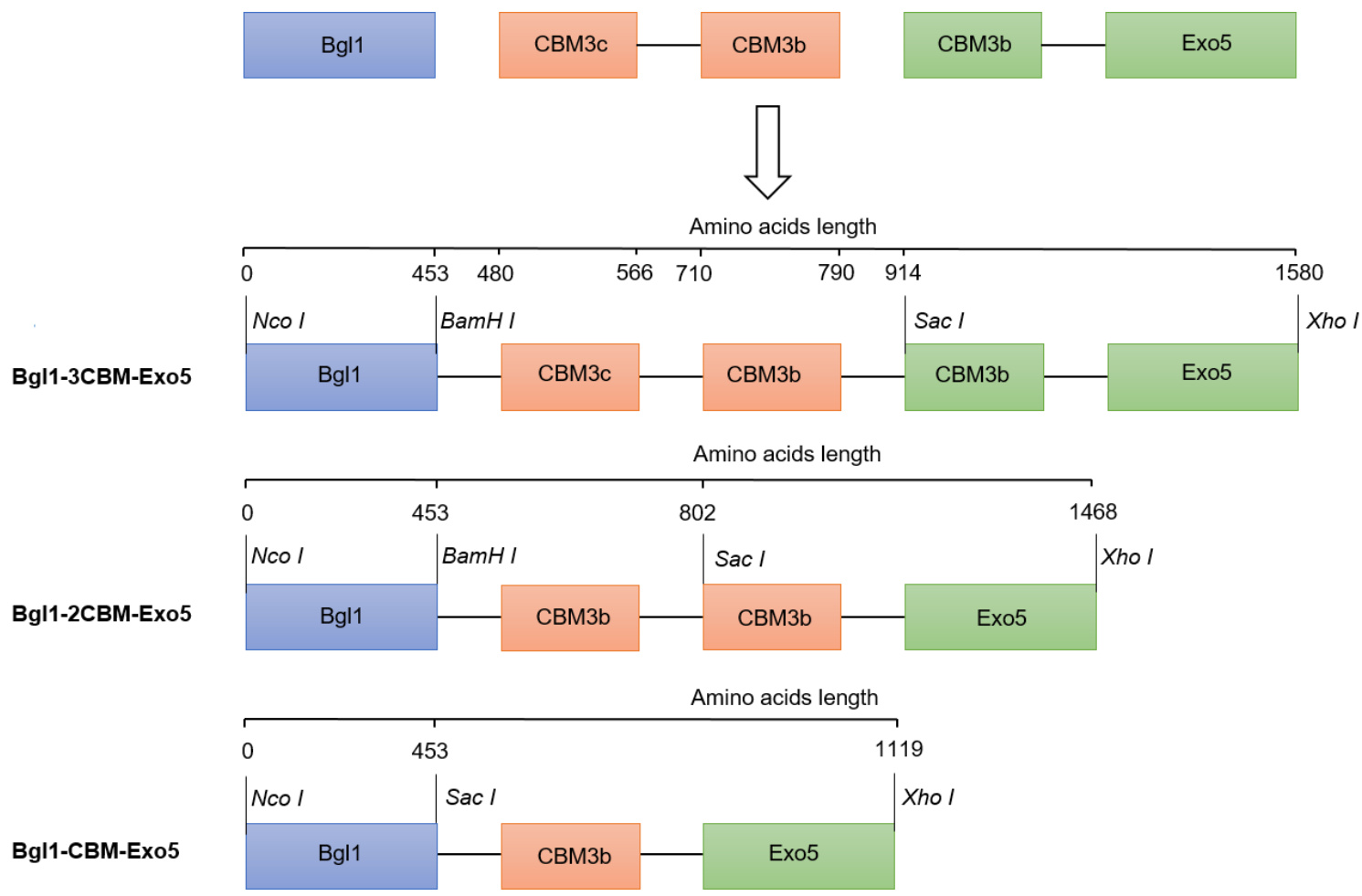

Fig. 1. A schematic representation for construction of the fusion enzymes

Thin layer chromatography (TLC) was used to detect $\beta$-glucosidase activities. A typical reaction mixture $(150 \mu \mathrm{L})$ include $50 \mu \mathrm{L}$ of $5 \mathrm{mM}$ cellobiose, $50 \mu \mathrm{L}$ of $50 \mathrm{mM}$ imidazole/potassium-phthalate buffer $(\mathrm{pH} \mathrm{5.5)}$, and $50 \mu \mathrm{L}$ of crude enzyme extract. The resulting reaction mixture was incubated at $70{ }^{\circ} \mathrm{C}$ for $30 \mathrm{~min}$. Then $50 \mu \mathrm{L}$ of hydrolysis products were spotted on the TLC plate and developed with n-butyl alcohol: acetic acid: water (2:1:1, by vol.). The hydrolysis products were detected by spraying the plate with methanol: sulfuric acid (9:1, v/v). In addition, the exoglucanase activities were determined by the dinitrosalicylic acid (DNS) assay. For this, reaction mixture $(150 \mu \mathrm{L})$ contained $50 \mu \mathrm{L}$ of $1 \%(\mathrm{w} / \mathrm{v}) \mathrm{CMC}-\mathrm{Na}, 50 \mu \mathrm{L}$ of $50 \mathrm{mM}$ imidazole/potassium-phthalate buffer ( $\mathrm{pH} 5.5$ ), and $50 \mu \mathrm{L}$ of crude enzyme extract. After incubating the reaction mixture at $70{ }^{\circ} \mathrm{C}$ for $30 \mathrm{~min}$, the reaction was terminated by adding $150 \mu \mathrm{L}$ DNS reagent followed by incubation at $100{ }^{\circ} \mathrm{C}$ for $5 \mathrm{~min}$. After the stipulated time, the mixture was placed in an ice bath. Then, $700 \mu \mathrm{L}$-sterilized water was added to each mixture and centrifuged at $10,000 \times \mathrm{g}$ for $2 \mathrm{~min}$. The reaction mixture without incorporating fusion enzymes was used as a control. 
Purification and characterization of the fusion enzymes

E. coli BL21(DE3) positive transformants were inoculated into $500 \mathrm{~mL}$ of LB medium and then induced by adding $\beta$-D-thiogalactoside (IPTG) with a final concentration of $0.5 \mathrm{mM}$ after $\mathrm{OD}_{600}$ reached 0.6 to 0.8 . Cells were harvested and washed using sterile water and resuspended in $20 \mathrm{~mL}$ binding buffer (Novagen, His Bind Purification kit). The cells were broken by sonication and heat-treated at $70{ }^{\circ} \mathrm{C}$ for $15 \mathrm{~min}$. The supernatant was collected and used to purification. The fusion proteins with His $(6 \mathrm{x})$ tags were applied on His Bind Purification kit (Novagen) and eluted using $100 \mathrm{mM}$ imidazole. The concentration of fusion proteins was quantified with a BCA protein assay kit (Real-Times, Beijing, China).

For determining the optimal $\mathrm{pH}$ of the fusion enzymes, nine buffers with a $\mathrm{pH}$ range of 4.0 to 8.0 were used in this assay. The reducing sugars released from hydrolyzing CMC-Na were determined by a DNS assay. One unit (U) of enzyme activity was defined as the amount of enzyme required to liberate $1 \mu \mathrm{mol}$ of glucose per min at $\mathrm{pH} 4.5$ and $80^{\circ} \mathrm{C}$. In order to determine the optimal temperatures of the purified enzymes, the reaction mixture containing $2 \mu \mathrm{g}$ of purified enzymes was incubated at a temperature range of 40 to $90{ }^{\circ} \mathrm{C}$ and $\mathrm{pH} 4.5$. The thermal stabilities of the fusion enzymes were measured by incubating enzymes at different temperatures for $2 \mathrm{~h}$. Moreover, the $\mathrm{pH}$ stabilities of the fusion enzymes were also determined following incubating enzymes into imidazole/potassium-phthalate buffer with a final concentration of $50 \mathrm{mM}$ at $65{ }^{\circ} \mathrm{C}$ for 2 h. Chemicals with a final concentration of $1 \mathrm{mM}$ and $10 \mathrm{mM}$ were added into the reaction mixture to investigate their effects on the fusion enzymes activities. Before the reaction, reagents were firstly added into the mixture with $50 \mathrm{mM}$ imidazole/potassium-phthalate buffer ( $\mathrm{pH} 4.5)$ and the diluted purified enzymes. Then, the mixture was incubated at $80{ }^{\circ} \mathrm{C}$ for $2 \mathrm{~h}$. Finally, $1 \%(w / v) \mathrm{CMC}-\mathrm{Na}$ was added into the mixture to start the reaction. At the same time, the fusion enzymes activities without the addition of chemicals were defined as $100 \%$.

\section{Measurement of degradation of insoluble substrates}

Filter paper (FP), crystalline cellulose (MCC), steam-pretreated rice straw (SPRS), $\mathrm{RS}$, and WS were used to detect the degradation of insoluble substrates by the fusion enzymes. Insoluble substrates were first washed twice to remove impurities. A $2 \mathrm{~mL}$ reaction mixture containing $50 \mathrm{mg}$ insoluble substrates, $1 \mathrm{~mL}$ of $50 \mathrm{mM}$ imidazole/ potassium-phthalate buffer ( $\mathrm{pH} 4.5$ ), and $1 \mathrm{~mL}$ of appropriate diluted purified enzymes containing $10 \mu \mathrm{g}$ of purified enzymes was prepared. The mixture was shaken $(200 \mathrm{rpm})$ at $80{ }^{\circ} \mathrm{C}$ for $4 \mathrm{~h}$. Afterward, the reaction was terminated by adding $\mathrm{Na}_{2} \mathrm{CO}_{3}$ at a final concentration of $200 \mathrm{mM}$, and the reducing sugars released were analyzed by a DNS assay. For this, $700 \mu \mathrm{L}$ supernatant of the reaction mixture was added into $300 \mu \mathrm{L}$ DNS reagent and incubated at $100{ }^{\circ} \mathrm{C}$ for $5 \mathrm{~min}$. After the designated time, the mixture was placed in an ice bath at once. Then, $1 \mathrm{~mL}$ of sterilized water was added into each mixture and centrifuged at $10,000 \times \mathrm{g}$ for $2 \mathrm{~min}$. Finally, the determination of $\mathrm{OD}_{520}$ was used to calculate enzymes activities. Moreover, for further detection of products hydrolyzed by the fusion enzymes, $200 \mu \mathrm{L}$ of reaction supernatant was spotted on a silica gel plate. The reaction mixture containing CBM-Exo5 was used as a control. 


\section{RESULTS AND DISCUSSION}

\section{Activities of the Crude Enzymes on Cellobiose}

Cellulases from thermophilic bacteria $C$. saccharolyticus are likely to be highly desirable for industrial applications ( $\mathrm{Hj}$ et al. 2008). However, Bgll from $C$. saccharolyticus is a rate-limiting enzyme for an industrial bioprocess (Yang et al. 2015). The microcrystalline cellulose could be degraded by Exo5, which exhibited lower activities (Park et al. 2011). Therefore, fused enzymes between Exo5 and Bgl1 were constructed, yielding Bg11-CBM-Exo5, Bgl1-2CBM-Exo5, and Bgl1-3CBM-Exo5 to improve the degradation efficiency of Exo5 and expanding its natural substrates utilization.

The crude proteins extracts were used as raw material to determine the activities of constructed fusion enzymes. $\beta$-glucosidase activities of the fusion enzymes were determined by TLC method. Lane 1 denoted glucose marker, whereas Lane 3, 4, and 5 showed that cellobiose had been degraded into glucose by the fused enzymes, which was denoted by arrows (Fig. 2). However, Lane 2 suggested that cellobiose could not be transformed into glucose by parental CBM-Exo5. Previously, Park et al. (2011) reported that cellobiose cannot be transformed into glucose by CBM-Exo5. Thus, all of the fusion enzymes had $\beta$-glucosidase activities.

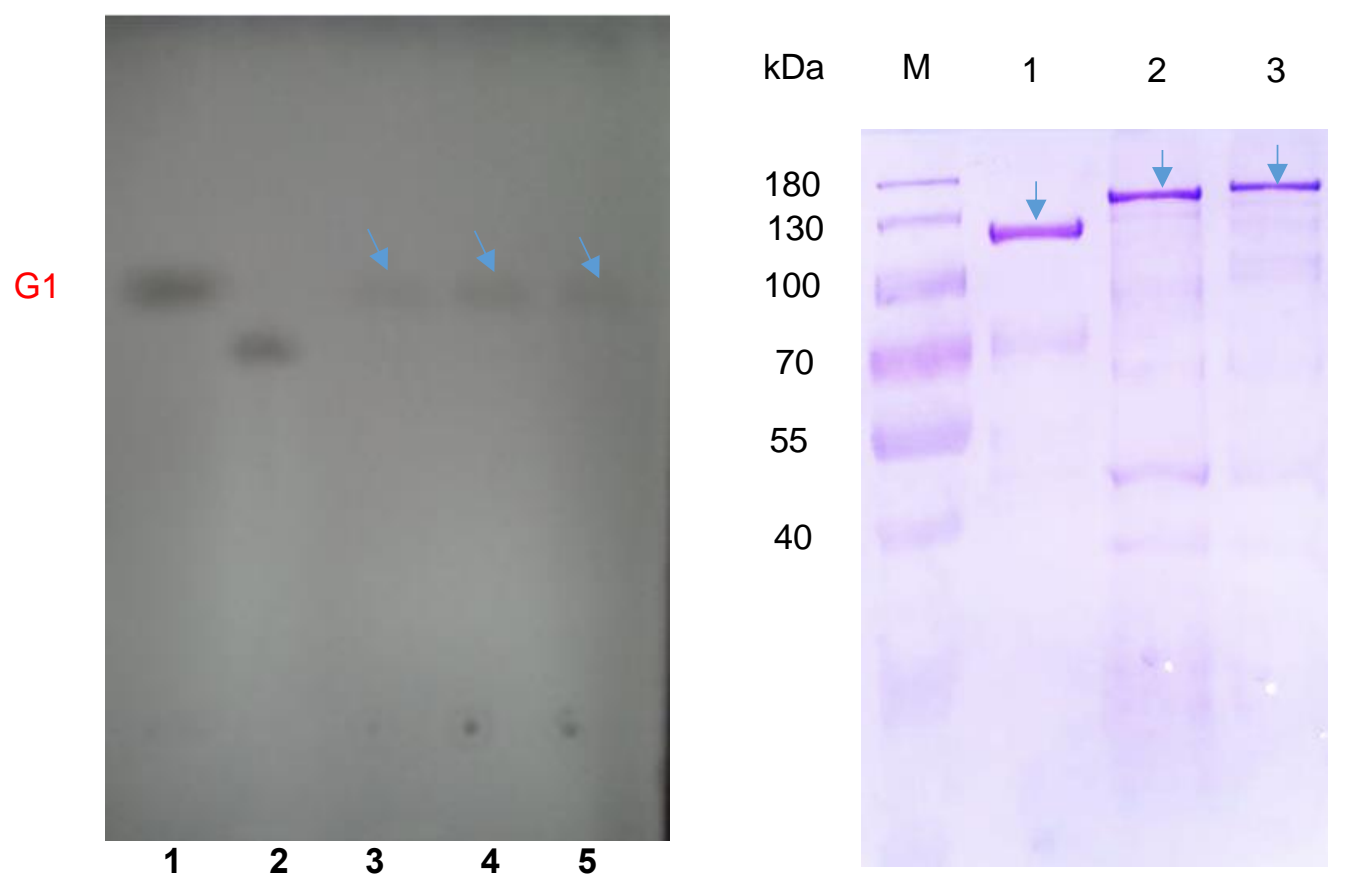

Fig. 2. TLC analysis of hydrolysis products of parental enzyme and the fusion enzymes. Lane 1: G1 denoted glucose marker. Lane 2, 3,4 and 5 indicated hydrolysis products of CBM-Exo5, Bgl1-CBM-Exo5, Bgl1-2CBMExo5, and Bgl1-3CBM-Exo5, respectively. Glucose product is denoted by arrows.

Fig. 3. SDS-PAGE analysis of the fusion proteins. M: Protein Ladder. Lane 1, 2, and 3: the purified proteins Bgl1-CBM-Exo5, Bgl12CBM-Exo5, and Bgl1-3CBM-Exo5, respectively, and the fusion proteins were denoted by arrows. 


\section{Purification and Characterization of the Fusion Enzymes}

The fusion proteins were purified using His Bind Purification kit for the characterization of the fusion enzymes. Lane $M$ indicated the protein ladder (Fig. 3). Lanes 1,2, and 3 represented the purified Bgl1-CBM-Exo5, Bgl1-2CBM-Exo5, and Bgl1-3CBM-Exo5, respectively, which are denoted by arrows. The molecular weights of Bgl1-CBM-Exo5, Bgl1-2CBM-Exo5, and Bgl1-3CBM-Exo5 were $128 \mathrm{kDa}, 153 \mathrm{kDa}$, and $163 \mathrm{kDa}$, respectively. The apparent molecular weights of the purified fusion proteins were similar to the theoretical molecular weights.

Among these fusion enzymes, the relative activities increased slightly when the temperature approached 70 to $80{ }^{\circ} \mathrm{C}$ and then decreased at $\geq 80{ }^{\circ} \mathrm{C}$. The optimal temperature of Bgl1-CBM-Exo5 and Bg11-2CBM-Exo5 was $80^{\circ} \mathrm{C}$, which was consistent with that of parental CBM-Exo5 (Park et al. 2011). However, the optimal temperature of Bgl1-3CBM-Exo5 decreased by $10{ }^{\circ} \mathrm{C}$ compared with other fusion enzymes, and it was the same as that of parental Bgl1 (Fig. 4 a) (Hong et al. 2009). The data also showed that activities of the fusion enzymes were relatively stable below $85{ }^{\circ} \mathrm{C}$, which reduced the cost of application. When incubated at $90{ }^{\circ} \mathrm{C}$, the fusion enzymes activities declined rapidly in $2 \mathrm{~h}$ (Fig. 4 b, c, and d). However, the activities of the fusion enzymes increased rapidly by incubating at $80{ }^{\circ} \mathrm{C}$ for $30 \mathrm{~min}$ (Fig. $4 \mathrm{~b}$ and d). The result indicated that the fusion enzymes may be stimulated by high temperatures. The optimal temperatures of the fusion enzymes were all 70 or $80{ }^{\circ} \mathrm{C}$, and they were thermostable at elevated temperatures, which was also beneficial in reducing the cost of storage. The optimal $\mathrm{pH}$

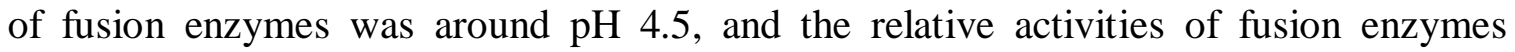
decreased slightly with increasing $\mathrm{pH}$. Overall, the fusion enzymes were observed to be partially acidic (Fig. $4 \mathrm{e}$ ). The curve of the fusion enzymes $\mathrm{pH}$ stabilities was consistent with that of the optimal $\mathrm{pH}$ (Fig. $4 \mathrm{e}$ and f). 

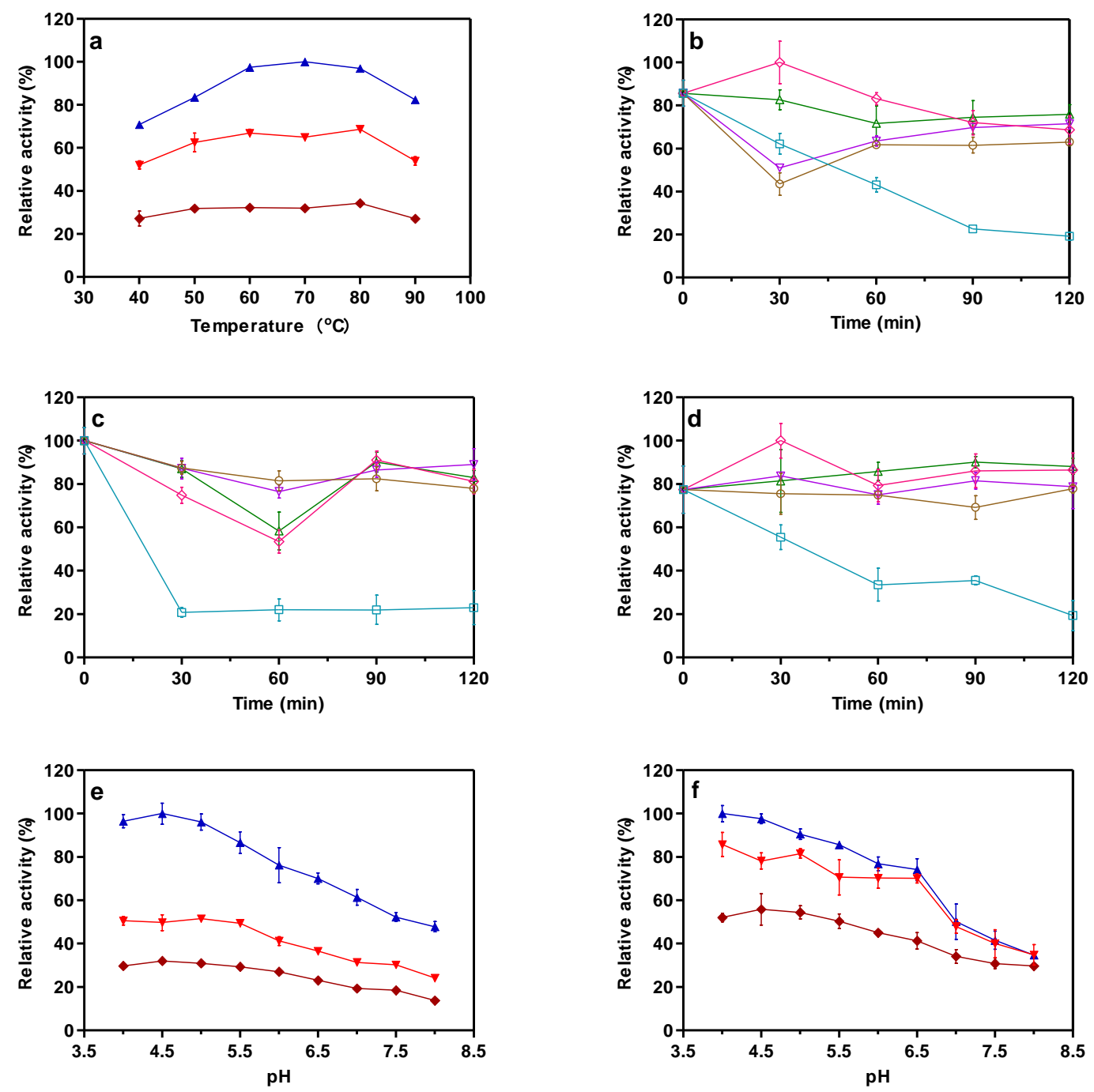

Fig. 4. Effects of temperature and $\mathrm{pH}$ on the activities and stabilities of the fusion enzymes. (a) Comparison of the optimal temperatures of the fusion enzymes. (b) Different temperatures on the stabilities of the Bgl1-CBM-Ex05, (c) Bgl1-2CBM-Ex05, and (d) Bgl1-3CBM-Ex05. (e) Comparison of the optimal $\mathrm{pH}$ of fusion enzymes. (f) Comparison of $\mathrm{pH}$ stability of the fusion enzymes. All the assays were conducted in triplicates, and error bars denote the standard deviation ( $\boldsymbol{\Delta}$ represents Bgl1-3CBM-Exo5; $\boldsymbol{\nabla}$ represents Bgl1-2CBM-Exo5; $\bullet$ represents Bgl1CBM-Exo5; $\triangle$ represents $70^{\circ} \mathrm{C} ; \nabla$ represents $75^{\circ} \mathrm{C}$; $\diamond$ represents $80^{\circ} \mathrm{C}$; o represents $85^{\circ} \mathrm{C}$; $\square$ represents $\left.90^{\circ} \mathrm{C}\right)$.

The effect of different reagents on the activities of the fusion enzymes was determined (Fig. 5). All of the fusion enzymes were activated by $\mathrm{CaCl}_{2}, \mathrm{MnCl}_{2}, \mathrm{MgCl}_{2}$, and $\mathrm{FeSO}_{4}$. Notably, the activities of fusion enzymes were increased by $200 \%$ due to the stimulating effect of $10 \mathrm{mM} \mathrm{MnCl}_{2}$. The results also indicated that $\mathrm{MnCl}_{2}$ played a key role in enhancing the activity of cellulases (Pei et al. 2017). A slight change in the fusion enzymes activities was recorded when $\mathrm{FeSO}_{4}, \mathrm{MgCl}_{2}, \mathrm{KCl}$, and $\mathrm{NaCl}$ were added into the reaction mixtures. In contrast, the fusion enzymes activities were inhibited by incorporating the varying concentration of chemicals, e.g., $1 \mathrm{mM}$ or $10 \mathrm{mM}$ EDTA, SDS, 
$\mathrm{CuSO}_{4}, \mathrm{ZnSO}_{4}$, and $\mathrm{FeCl}_{3}$. The activities of the fusion enzymes were reduced dramatically by the addition of $10 \mathrm{mM} \mathrm{SDS}, \mathrm{CuSO}_{4}, \mathrm{ZnSO}_{4}$, and $\mathrm{FeCl}_{3}$.
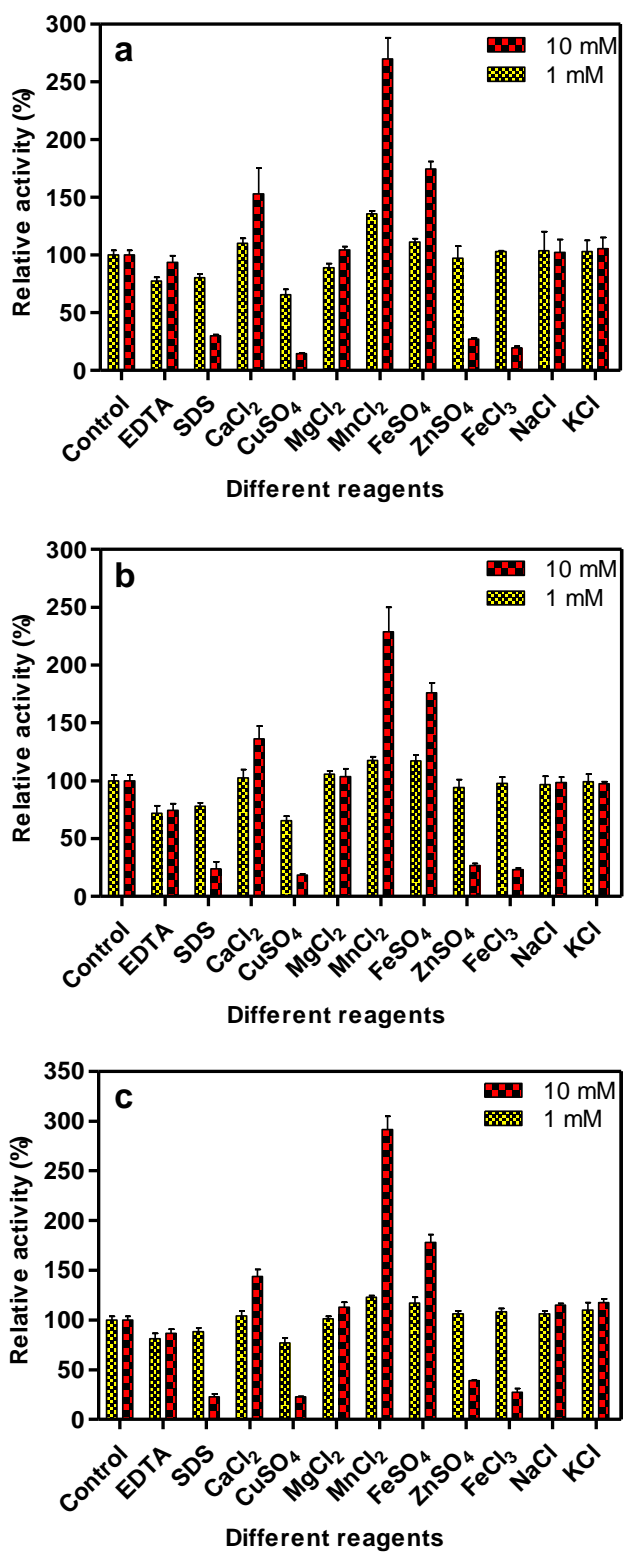

Fig. 5. The effects of reagents on the fusion enzymes activities. (a) The effects of chemicals on the activities of Bgl1-CBM-Exo5, (b) Bgl1-2CBM-Exo5, and (c) Bgl1-3CBM-Exo5

\section{Fusion Enzymes Specific Activities}

All the tested substrates were efficiently degraded by the action of fusion enzymes (Table 2). However, the maximum amount of sugars was released from the hydrolysis of MCC by the fusion enzymes. Among the fusion enzymes, Bgl1-3CBM-Exo5 exhibited the highest activities on all of the substrates. Notably, FP, MCC, SPRS, WS, and RS were degraded into cellobiose by parental CBM-Exo5 and the fusion enzymes (Fig. 6). Interestingly, cellobiose released from the hydrolysis of these substrates by fusion enzymes was lower as compared with CBM-Exo5. However, glucose released from the 
hydrolysis of these substrates by the fusion enzymes was recorded to be higher, which may attribute to Bgl1 eliminating more hydrolysis products of Exo5 (Rizk et al. 2012) (Fig. 6). The released glucose might be efficiently used to fermentative production of bioethanol (Table 2 and Fig. 4) (Park et al. 2011). It was obvious that parental Bgll and Exo5 function together by an intramolecular synergy (Riedel and Bronnenmeier 1998).
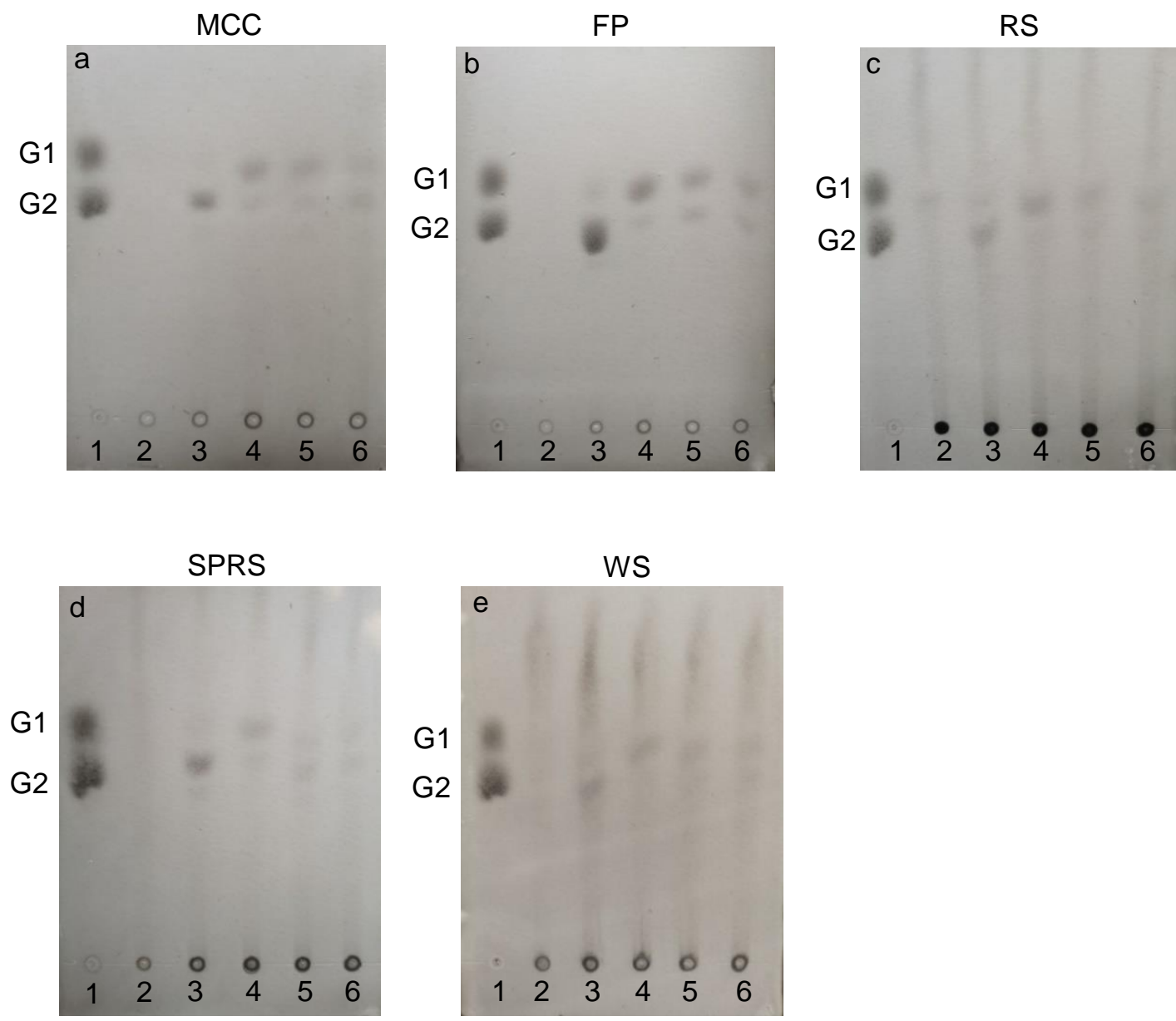

Fig. 6. Schematic illustration of hydrolysis products of the parental CBM-Exo5 and the fusion enzymes. 1 denoted the marker, including glucose (G1) and cellobiose (G2); 2 represented the control without the addition of the enzymes; 3-6 indicated products of CBM-Exo5, Bgl1-CBMEx05, Bgl1-2CBM-Exo5 and Bgl1-3CBM-Exo5 hydrolyzing different natural substrates, respectively; a, b, c, d, and e indicated MCC, FP, RS, SPRS and WS degraded by CBM-Exo5 and the fusion enzymes. 
Table 2. Activities of the Fusion Enzymes on FP, MCC, SPRS, RS, and WS

\begin{tabular}{|c|c|c|c|c|c|c|c|}
\hline \multirow{2}{*}{ Protein } & \multicolumn{6}{|c|}{ 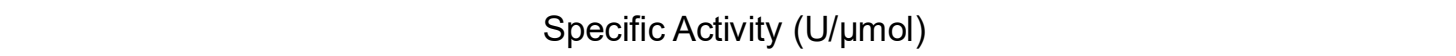 } & \multirow{2}{*}{ Reference } \\
\hline & $\mathrm{CMC}-\mathrm{Na}$ & FP & MCC & SPRS & RS & WS & \\
\hline Bgl1-CBM-Exo5 & $137.3 \pm 4.4$ & $19.5 \pm 2.1$ & $36.5 \pm 13.5$ & $12.4 \pm 2.1$ & $12.0 \pm 3.5$ & $12.0 \pm 1.7$ & This study \\
\hline Bgl1-2CBM-Exo5 & $275.6 \pm 4.6$ & $6.0 \pm 1.3$ & $34.4 \pm 2.7$ & $14.6 \pm 2.8$ & $7.3 \pm 1.6$ & $20.4 \pm 4.0$ & This study \\
\hline Bgl1-3CBM-Exo5 & $401.2 \pm 1.1$ & $39.0 \pm 10.3$ & $76.4 \pm 13.7$ & $22.1 \pm 12.4$ & $39.2 \pm 6.6$ & $30.8 \pm 5.3$ & This study \\
\hline CBM-Exo5 & ND & ND & 27.8 & ND & ND & ND & Park et al. (2011) \\
\hline $\mathrm{CtCA}-\mathrm{CcBG}$ & 251.3 & ND & ND & ND & ND & ND & Lee et al. (2011) \\
\hline CelYZ & 150 & ND & 7.4 & ND & ND & ND & Riedel and Bronnenmeier (1998) \\
\hline CBMan5B/Cel44A & ND & $12.7 \pm 0.2$ & $5.3 \pm 0.8$ & ND & ND & ND & Ye et al. (2012) \\
\hline CelA & ND & $13.1 \pm 0.3$ & $22.8 \pm 1.3$ & ND & ND & ND & Yi et al. (2013) \\
\hline CbCel9B/Man5A & ND & $16.12 \pm 2.86$ & $10.15 \pm 0.51$ & ND & ND & ND & Su et al. (2012) \\
\hline
\end{tabular}

ND: Not detected; Assays were conducted in triplicates. 
Exoglucanase CelY and endoglucanase CelZ from the cellulolytic thermophile Clostridium stercorarium were also fused and analyzed (Riedel and Bronnenmeier 1998). Data showed that MCC could be degraded by CelYZ. Compared with CelYZ, the activities of the fusion enzymes on MCC increased by 3.65- to 9.32-fold (Table 2). It has been shown that MCC and FP are degraded by natural bifunctional cellulases ( $\mathrm{Su}$ et al. 2012; Ye et al. 2012; Yi et al. 2013). However, the activities of the fused enzymes were increased by 0.54 - to 2.07-fold compared with natural bifunctional cellulases (Table 2). CtCA-CcBG, fused between cellulosomal exoglucanase and $\beta$-glucosidase, was similar to these fusion enzymes (Lee et al. 2011). Among the fusion enzymes, the activity of Bgl13CBM-Exo5 was only increased by 0.60 -fold compared to CtCA-CcBG (Table 2). This suggested that the increased activity mainly attributed to the enhanced concentration of CBMs on the substrates (Alkotaini et al. 2016). CBM3b and CBM3c were also essential for substrates binding and processing, respectively (Zhang et al. 2018).

Although the fusion enzymes can decompose MCC and other un-pretreated biomass, exoglucanase and $\beta$-glucosidase are two rate-limiting enzymes employed in industry. Endoglucanase is usually regarded as the first step for decomposing MCC. Construction of a bifunctional enzyme between endoglucanase and exoglucanase or endoglucanase and $\beta$-glucosidase with CBMs might be a promising choice for highly efficient degradation of MCC. The CBMs fused into two catalytic domains were more accessible to substrates, which was also beneficial for exploring the new catalytic mechanism of cellulase with multiple catalytic domains.

\section{CONCLUSIONS}

1. Bifunctional cellulases, Bg11-CBM-Exo5, Bgl1-2CBM-Exo5, and Bg11-3CBMExo5, were constructed and expressed in E. coli BL21(DE3). Bgl1 alone had no detectable activity on CMC-Na. However, the fusion enzymes with unique properties were obtained.

2. The fusion enzymes not only had both functions but also displayed potential for a wider spectrum of substrates. As a result, FP, MCC, SPRS, and RS were efficiently degraded into glucose by the fusion enzymes rather than only cellobiose.

3. $\mathrm{CaCl}_{2}, \mathrm{MnCl}_{2}, \mathrm{MgCl}_{2}$, and $\mathrm{FeSO}_{4}$ activated the fusion enzymes. Remarkably, activities of the fusion enzymes by $\mathrm{MnCl}_{2}$ increased by $200 \%$ with $10 \mathrm{mM} \mathrm{MnCl}_{2}$.

4. The optimal $\mathrm{pH}$ and temperature of the fusion enzymes were 4.5 and $80{ }^{\circ} \mathrm{C}$, respectively. The fusion enzymes were thermostable below $85^{\circ} \mathrm{C}$.

\section{ACKNOWLEDGMENTS}

This work was supported by the National Natural Science Foundation of China Grants 21576110 and 21706089, Open Project of Jiangsu Provincial Engineering Laboratory for Biomass Conversion and Process Integration (No. PELBCPL2014003) and Jiangsu Provincial Key Construction Laboratory of Probiotics Preparation Open Project (No. JSYSZJ2017007 and JSYSZJ2018004). 


\section{REFERENCES CITED}

Alkotaini, B., Han, N. S., and Kim, B. S. (2016). "Enhanced catalytic efficiency of endo$\beta$-agarase I by fusion of carbohydrate-binding modules for agar prehydrolysis," Enzyme Microb. Tech. 93-94, 142-149. DOI: 10.1016/j.enzmictec.2016.08.010

Brunecky, R., Alahuhta, M., Xu, Q., Donohoe, B. S., Crowley, M. F., Kataeva, I., and Bomble, Y. J. (2013). "Revealing nature's cellulase diversity: The digestion mechanism of Caldicellulosiruptor bescii CelA," Science 342(6165), 1513-1516. DOI: $10.1126 /$ science. 1244273

Blumerschuette, S. E., Giannone, R. J., Zurawski, J. V., Ozdemir, I., Ma, Q., and Yin, Y. (2012). "Caldicellulosiruptor core and pangenomes reveal determinants for noncellulosomal thermophilic deconstruction of plant biomass," J. Bacteriol. 194(15), 4015. DOI: 10.1128/JB.00266-12

Duedu, K. O., and French, C. E. (2016). "Characterization of a Cellulomonas fimi, exoglucanase/xylanase-endoglucanase gene fusion which improves microbial degradation of cellulosic biomass," Enzyme Microb Technol. 93-94, 113-121. DOI: 10.1016/j.enzmictec.2016.08.005

Hj, V. D. W., Verhaart, M. R., Vanfossen, A. L., Willquist, K., Lewis, D. L., and Nichols, J. D. (2008). "Hydrogenomics of the extremely thermophilic bacterium Caldicellulosiruptor saccharolyticus," Appl. Environ. Microb. 74(21), 6720-6729. DOI: 10.1023/A:1012446007088

Hong, S. Y., Lee, J. S., Cho, K. M., Math, R. K., Kim, Y. H., and Hong, S. J. (2006). "Assembling a novel bifunctional cellulose-xylanase from Thermotoga maritima by end-to-end fusion," Biotechnol Lett. 28(22), 1857-1862. DOI: 10.1007/s10529-0069166-8

Hong, S. Y., Lee, J. S., Cho, K. M., Math, R. K., Kim, Y. H., and Hong, S. J. (2007). "Construction of the bifunctional enzyme cellulase- $\beta$-glucosidase from the hyperthermophilic bacterium Thermotoga maritima," Biotechnol. Lett. 29(6), 931936. DOI: 10.1007/s10529-007-9334-5

Hong, M. R., Kim, Y. S., Park, C. S., Lee, J. K., and Oh, D. K. (2009). "Characterization of a recombinant $\beta$-glucosidase from the thermophilic bacterium Caldicellulosiruptor saccharolyticus," J. Biosci. Bioeng. 108(1), 36-40. DOI: 10.1016/j.jbiosc.2009.02.014

Kim, H. M., Jung, S., Lee, K. H., Song, Y., and Bae, H. J. (2015). "Improving lignocellulose degradation using xylanase-cellulase fusion protein with a glycineserine linker," Int. J. Biol. Macromol. 73, 215-221. DOI: 10.1016/j.ijbiomac.2014.11.025

Lee, H. L., Chang, C. K., Teng, K. H., and Liang, P. H. (2011). 'Construction and characterization of different fusion proteins between cellulases and $\beta$-glucosidase to improve glucose production and thermostability," Bioresource Technol. 102(4), 3973-3976. DOI: 10.1016/j.biortech.2010.11.114

Mariano, D. C. B., Leite, C., Santos, L. H. S., Marins, L. F., Machado, K. S., and Werhli, A. V. (2014). "Characterization of glucose-tolerant $\beta$-glucosidases used in biofuel production under the bioinformatics perspective: A systematic review," Genet. Mol. Res. 16(3). DOI: 10.4238/gmr16039740

Park, J. I., Kent, M. S., Datta, S., Holmes, B. M., Huang, Z., and Simmons, B. A. (2011). "Enzymatic hydrolysis of cellulose by the cellobiohydrolase domain of celB from the hyperthermophilic bacterium Caldicellulosiruptor saccharolyticus," Bioresource Technol. 102(10), 5988-5994. DOI: 10.1016/j.biortech.2011.02.036 
Riedel, K., and Bronnenmeier, K. (1998). "Intramolecular synergism in an engineered exo-endo-1,4- $\beta$-glucanase fusion protein," Mol. Microbiol. 28(4), 767-775. DOI: 10.1046/j.1365-2958.1998.00834.x

Rizk, M., Antranikian, G., and Elleuche, S. (2012). "End-to-end gene fusions and their impact on the production of multifunctional biomass degrading enzymes," Biochem. Bioph. Res. Co. 428(1), 1-5. DOI: 10.1016/j.bbrc.2012.09.142

Singh, G., Verma, A. K., and Kumar, V. (2016). "Catalytic properties, functional attributes and industrial applications of $\beta$-glucosidases," 3 Biotech. 6(1), 3. DOI: 10.1007/s13205-015-0328-Z

Shi, H., Chen, Y., Peng, W., Wang, P., Zhao, Y., Li, X., Wang, F., and Li, X. (2018). "Fusion endoglucanase Cel12B from Thermotoga maritima with cellulose binding domain," BioResources 13(2), 4497-4508. DOI: 10.15376/biores.13.2.4497-4508

Su, X., Mackie, R. I., and Cann, I. K. O. (2012). "Biochemical and mutational analyses of a multidomain cellulase/mannanase from Caldicellulosiruptor bescii," Appl. Environ. Microb. 78(7), 2230-2240. DOI: 10.1128/AEM.06814-11

Yang, F., Yang, X., Li, Z., Du, C., Wang, J., and Li, S. (2015). 'Overexpression and characterization of a glucose-tolerant $\beta$-glucosidase from $T$. aotearoense with high specific activity for cellobiose," Appl microbiol Biot. 99(21), 8903-8915. DOI: 10.1007/s00253-015-6619-9.

Ye, L., Su, X., Schmitz, G. E., Moon, Y. H., Zhang, J., and Mackie, R. I. (2012). "Molecular and biochemical analyses of the gh44 module of cbman5b/cel44a, a bifunctional enzyme from the hyperthermophilic bacterium Caldicellulosiruptor bescii," Appl. Environ. Microb. 78(19), 7048-7059. DOI: 10.1128/AEM.02009-12

Yi, Z., Su, X., Revindran, V., Mackie, R. I., and Cann, I. (2013). "Molecular and biochemical analyses of cbcel9a/cel48a, a highly secreted multi-modular cellulase by caldicellulosiruptor bescii during growth on crystalline cellulose," PLOS One 8. DOI: 10.1371/journal.pone.0084172

Zhao, C., Chu, Y., Li, Y., Yang, C., Chen, Y., and Wang, X. (2017). "High-throughput pyrosequencing used for the discovery of a novel cellulase from a thermophilic cellulose-degrading microbial consortium," Biotechnol. Lett. 39(1), 123-131. DOI: 10.1007/s10529-016-2224-y

Zhang, K. D., Li, W., Wang, Y., Zheng, Y. L., Tan, F. C., and Ma, X. Q. (2018). "Processive degradation of crystalline cellulose by a multimodular endoglucanase via a wirewalking mode," Biomacromolecules DOI: 10.1021/acs.biomac.8b00340

Article submitted: February 23, 2019; May 25, 2019; Revised version received: June 19, 2019; Accepted: June 24, 2019; Published: July 5, 2019.

DOI: 10.15376/biores.14.3.6767-6780 